\title{
Dynamic Pricing Model for the Operation of Closed-Loop Supply Chain System
}

\author{
Jiawang $X u^{1,2}$, Yunlong Zhu' ${ }^{1}$ \\ ${ }^{1}$ Shenyang Institute of Automation, Chinese Academy of Sciences, Shenyang, China \\ ${ }^{2}$ School of Economics \& Management, Shenyang Aerospace University, Shenyang, China \\ E-mail: ccb867321@yahoo.com.cn \\ Received August 2, 2011; revised August 29, 2011; accepted September 6, 2011
}

\begin{abstract}
A class of closed-loop supply chain system consisting of one manufacturer and one supplier is designed, in which re-distribution, remanufacturing and reuse are considered synthetically. The manufacturer is in charge of recollecting and re-disposal the used products. Demands of ultimate products and collecting quantity of used products are described as the function of prices and reference prices. A non-linear dynamic pricing model for this closed-loop supply chain is established. A numerical example is designed, and the results of this example verified the model's validity to price for the operation of closed-loop supply chain system.
\end{abstract}

Keywords: Closed-Loop Supply Chain, Manufacturing/Remanufacturing, Pricing, Dynamic Programming

\section{Introduction}

There are numerous researches on closed-loop supply chain system which address many various topics from definition to practical cases in real industry. Many analytic and quantitative approaches are also found in various problems such as forecasting, production planning/ control, inventory control/management, and location. For example, the impact of remanufacturing in economy was studied by Ferrer and Ayres [1], and more fundamentally, Sundin and Bras [2] provided arguments for why used products should be remanufactured. A good overview on quantitative models for recovery production planning and inventory control was given by Fleischmann et al. [3]. Der Laan and Salomon [4] proposed a hybrid manufacturing/remanufacturing system with stocking points for serviceable and remanufacturable products. Jayaraman et al. [5] proposed a general mixed-integer programming model and solution procedure for a reverse distribution problem focused on the strategic level. Moreover, Kim et al. [6] dealt with remanufacturing execution at operational level. They proposed a general framework for remanufacturing system in reverse logistics environment and a mathematical model to maximize the total cost savings by optimally deciding the quantity of parts to be processed at each remanufacturing facilities, the number of purchased parts from subcontractor.
In the course of closed-loop supply chain system operations, it is also very important to decide the prices of ultimate products and the collecting prices of used products. Recently, Ray and Boyaci [7] studied the optimal pricing/trade-in strategies for durable, remanufacturable products. They focused on the scenario where the replacement customers were only interested in trade-ins. In this setting, they studied three pricing schemes: 1) uniform price for all customers, 2) age-independent price differentiation between new and replacement customers, and 3) age-dependent price differentiation between new and replacement customers. Gu et al. [8] studied the price decisions of recycled products based on the reverse supply chain between the manufacturer and the retailer by using game theory. Two non-cooperative game equilibrium (Stackelberg equilibrium and Nash equilibrium) and a cooperative game equilibrium (coordination in price decision) were obtained. Guide [9] researched the optimal collect decision when used product quality is uncertain, and Samar [10] studied the optimal price and collect policy for reverse logistics in electronic business. Liang et al. [11] proposed a model to evaluate the acquisition price of the used products. This model links the used product acquisition price with the sale price of used product but assumes other costs such as logistics and remanufacturing to be deterministic. Different from these researches above, a non-linear dynamic programming model is established in this paper, we study the dynamic 
pricing problems on ultimate products and used products for closed-loop supply chain with remanufacturing from the view of operation management.

\section{Descriptions}

\subsection{Framework for Closed-Loop Supply Chain System}

Considering a multi-stage closed-loop supply chain system consisting of one manufacturer and one supplier, in which re-distribution, remanufacturing and reuse are considered synthetically. The manufacturer is in charge of recollecting and re-disposal the used products. According to the status of used products, the manufacturer has four alternatives for re-disposing: 1) Repair. Some used products are repaired and sold with new products in the same market (here, we assume that product comes from used product repairing is same as new product); 2) Disassemble. Some used products are disassembled, and parts are brought back to "as new" conditions; 3) Decompose. Some used product can't be repaired or disassembled are decomposed to raw materials and be returned to supplier as his raw materials; 4) Discard. Other used products can't be reused are discarded.

At each stage, the manufacturer has two alternatives for supplying materials: either ordering the required materials to suppliers or overhauling used products and bringing those back to "as new" conditions. The quantity of manufacturer's outputs is determined by customers' demands and the outputs of used products repairing. The supplier product the materials which manufacturer ordering, his required raw materials come from the raw materials market and the outputs of used products decomposing. The framework for closed-loop supply chain system is shown as Figure 1.

\subsection{Notations}

Subscript:

$$
\begin{aligned}
& j \text { ultimate product }(j=1, \cdots, J) \text {; } \\
& i \text { material of manufacturer }(i=1, \cdots, I) \text {; }
\end{aligned}
$$

$t$ stage $(t=1, \cdots, T)$;

$h$ raw material $(h=1, \cdots, H)$

Decision variable:

$p_{i t}$ price of ultimate product $j$ at stage $t$;

$r_{j t}$ collecting price of used product $j$ at stage $t$;

$v_{j t}$ sales quantity of ultimate product $j$ at stage $t$;

$z_{j t}$ outputs of ultimate product $j$ at stage $t$;

$z_{j t}^{L}$ inventories of ultimate product $j$ at stage $t$;

$y_{i t}^{L}$ inventories of material $i$ at stage $t$;

$b_{i t}$ orders of material $i$ at stage $t$;

$l_{i t}$ supplier's delivery quantities of material $i$ at stage $t$

$x_{i t}$ supplier's production quantities of material $i$ at stage $t$;

$x_{i t}^{L} \quad$ supplier's inventories of material $i$ at stage $t$.

Parameters:

$R_{j t}$ collecting quantity of used product $j$ at stage $t$;

$d_{j t}$ demand of ultimate product $j$ at stage $t$;

$q_{\text {it }}$ price of material $i$ at stage $t$;

$c_{j}^{z}$ unit variable manufacturing cost of ultimate product $j$;

$h_{j}^{z}$ unit inventory cost of ultimate product $j$;

$h_{i}^{y}$ unit inventory cost of material $i$;

$\alpha_{j}^{k}$ capacity consuming rate of ultimate product $j$;

$K^{\max }$ manufacture's maximum production capacity;

$z_{j 0}^{L^{\prime}} \quad$ initial inventory of ultimate product $j$;

$o_{j}^{z}$ occupied inventory of unit ultimate product $j$;

$z^{\mathrm{L}^{\max }}$ total inventory level of ultimate products;

$s_{i j}^{y}$ BOM coefficient of ultimate product $j$ to material $i$;

$y_{i 0}^{L^{\prime}} \quad$ initial inventory of material $i$;

$o_{i}^{y}$ occupied inventory of unit material $i$;

$y^{\mathrm{L}^{\max }}$ total inventory level of materials;

$m_{h t}$ price of raw material $h$ at stage $t$;

$c_{i}^{x}$ unit variable cost of material $i$;

$s_{h i}^{r}$ BOM coefficient of material $i$ to raw material $h$;

$h_{i}^{x}$ unit inventory cost of material $i$;

$\alpha_{i}^{g} \quad$ capacity consuming rate of material $i$;

$G^{\max }$ supplier's maximum production capacity avail-

able;

$x_{i 0}^{L^{\prime}} \quad$ initial inventory of material $i$;

$o_{i}^{x}$ occupied inventory of unit material $i$;

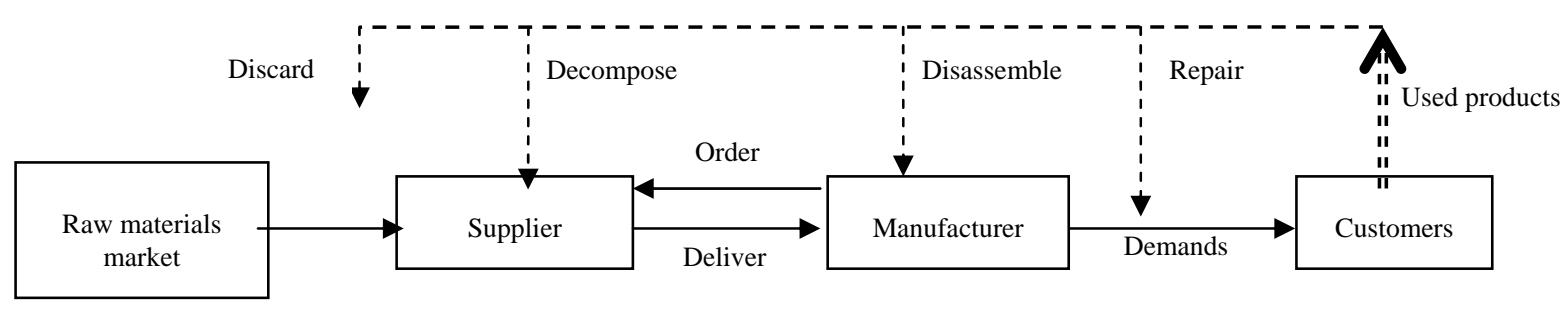

Figure 1. Framework for closed-loop supply chain system. 
$x^{L^{\max }}$ total inventory level of materials;

$s_{h t}$ supply quantity of raw material $h$ at stage $t$;

$w_{j t}$ average price of raw materials decomposed from used product $j$ at stage $t$;

$\alpha_{j t}^{1}, \quad \alpha_{j t}^{2}$ and $\alpha_{j t}^{3}$ are repairing rate, disassembling rate and decomposing rate of used product $j$ at stage $t$ respectively, and $\alpha_{j t}^{1}+\alpha_{j t}^{2}+\alpha_{j t}^{3} \leq 1$;

$\gamma_{j t}^{1}, \quad \gamma_{j t}^{2}$ and $\gamma_{j t}^{3}$ are unit repairing cost, disassembling cost and decomposing cost of used product $j$ at stage $t$ respectively, and $\gamma_{j t}^{1}<\gamma_{j t}^{2}<\gamma_{j t}^{3}$;

$d_{j}$ demand of ultimate product $j$ neglecting the impacts of price and vendition effort;

$e_{j}$ collecting quantity of used product $j$ neglecting the impacts of collecting price and collecting efforts;

$\alpha_{j}$ demand sensitive coefficient of ultimate product $j$ to the price;

$\beta_{j}$ demand sensitive coefficient of ultimate product $j$ to the variation of price;

$\varepsilon_{j}$ collecting quantity sensitive coefficient of used product $j$ to collecting price;

$\eta_{j}$ collecting quantity sensitive coefficient of used product $j$ to the variation of collecting price.

\subsection{Hypotheses}

1) The process of product manufacturing and used product remanufacturing are synchronously, and the outputs' quality from remanufacturing is the same as that of manufacturing, that is, the selling prices of the outputs from manufacturing and from remanufacturing are uniform;

2) Demand of ultimate product decreases along with the raising of selling price as well as the increment of selling price. For research convenient, we set

$d_{j t}=d_{j}-\alpha_{j} p_{j t}-\beta_{j}\left(p_{j t}-p_{j, t-1}\right)$;

3) Collecting quantity of used product increases along with the raising of collecting price as well as the increment of collecting price. We set

$R_{j t}=e_{j}+\varepsilon r_{j t}+\eta\left(r_{j t}-r_{j, t-1}\right)$.

\section{Pricing Model}

In the closed-loop supply chain system shown as Figure 1, we consider three operation objectives: 1) At each stage, operation of the closed-loop supply chain system should realize coordination of participants, namely the supplier's delivery quantity is nicely equal to the manufacturer's order quantity. 2) The Manufacturer pursues profits maximization. 3)The supplier pursues profits maximization. These objectives can be described as follows:

$$
b_{i t}=l_{i t} \quad \forall i, t
$$

$$
\begin{aligned}
\max C^{P}= & \sum_{t=1}^{T}\left[\sum_{j=1}^{J}\left(p_{j t} v_{j t}-c_{j}^{z} z_{j t}-h_{j}^{z} z_{j t}^{L}-\sum_{i=1}^{I}\left(q_{i t} b_{i t}+h_{i}^{y} y_{i t}^{L}\right)\right]\right. \\
& +\sum_{t=1}^{T} \sum_{j=1}^{J}\left\{w_{j t} R_{j t} \alpha_{j k}^{3} \sum_{h=1}^{H} \sum_{i=1}^{I}\left(s_{i j}^{y} s_{h i}^{r}\right)\right\} \\
& -\sum_{t=1}^{T} \sum_{j=1}^{J}\left[R_{j t}\left(r_{j t}+\alpha_{j t}^{1} \gamma_{j t}^{1}+\alpha_{j t}^{2} \gamma_{j t}^{2}+\alpha_{j t}^{3} \gamma_{j t}^{3}\right)\right] \\
\max C^{S}= & \sum_{t=1}^{T}\left[\sum_{i=1}^{I}\left(q_{i t} l_{i t}-h_{i}^{X} x_{i t}^{L}-\left[c_{i}^{X}+\left(\sum_{h=1}^{H} m_{h t} s_{h i}^{r}\right)\right] x_{i t}\right)\right] \\
& -\sum_{t=1}^{T} \sum_{j=1}^{J}\left\{w_{j t} \cdot R_{j t} \cdot \alpha_{j t}^{3} \cdot \sum_{h=1}^{H} \sum_{i=1}^{I}\left(s_{i j}^{y} s_{h i}^{r}\right)\right\}
\end{aligned}
$$

where, $C^{P}$ is Manufacturer's profit, and $C^{S}$ is supplier's profit.

Transform 3 expressions above to objective programming form, the operation model for the operation of closed-loop supply chain system can be rewritten as follows.

Objective function:

objective $1: \min \sum_{t=1}^{T} \sum_{i=1}^{I}\left(d_{i t}^{-}+d_{i t}^{+}\right)$;

objective $2: \min d_{P}^{-}$;

objective $3: \min d_{S}^{-}$;

where, $d_{i t}^{-}$and $d_{i t}^{+}$are supplier's delivery quantity of material $i$ at stage $t$ when it's deficient and superfluous respectively, $d_{p}^{-}$is deficient quantity of manufacturer's objective profit, $d_{S}^{-}$is deficient quantity of supplier's objective profit.

Objective restrictions:

$$
\begin{aligned}
-b_{i t}+l_{i t}+d_{i t}^{-}-d_{i t}^{+} & =0 \quad \forall i, t \\
C^{P}+d_{P}^{-}-d_{P}^{+} & =M_{P}
\end{aligned}
$$

$$
\begin{gathered}
C^{P}-\sum_{t=1}^{T}\left[\sum_{j=1}^{J}\left(p_{j t} v_{j t}-c_{j}^{z} z_{j t}-h_{j}^{z} z_{j t}^{L}-\sum_{i=1}^{I}\left(q_{i t} b_{i t}+h_{i}^{y} y_{i t}^{L}\right)\right]\right. \\
-\sum_{t=1}^{T} \sum_{j=1}^{J}\left\{w_{j t} R_{j t} \alpha_{j k}^{3} \sum_{h=1}^{H} \sum_{i=1}^{I}\left(s_{i j}^{y} s_{h i}^{r}\right)\right\} \\
+\sum_{t=1}^{T} \sum_{j=1}^{J}\left[R_{j t}\left(r_{j t}+\alpha_{j t}^{1} \gamma_{j t}^{1}+\alpha_{j t}^{2} \gamma_{j t}^{2}+\alpha_{j t}^{3} \gamma_{j t}^{3}\right)\right] \leq 0 \\
C^{S}-\sum_{t=1}^{T}\left[\sum_{i=1}^{I}\left(q_{i t} l_{i t}-h_{i}^{x} x_{i t}^{L}-\left[c_{i}^{x}+\left(\sum_{h=1}^{H} m_{h t} s_{h i}^{r}\right)\right] x_{i t}\right)\right] \\
+\sum_{t=1}^{T} \sum_{j=1}^{J}\left\{w_{j t} \cdot R_{j t} \cdot \alpha_{j t}^{3} \cdot \sum_{h=1}^{H} \sum_{i=1}^{I}\left(s_{i j}^{y} s_{h i}^{r}\right)\right\} \leq 0
\end{gathered}
$$

where, $M_{P}$ is a maximum objective profit the manufacturer expected and it's a constant, $M_{S}$ is a maximum 
objective profit the supplier expected and it's also a constant.

Absolute restrictions:

Supplier's production capacity satisfies

$$
\sum_{i=1}^{I} \alpha_{i}^{g} x_{i t} \leq G^{\max } \quad \forall t
$$

Supplier's inventory of product satisfies

$$
\begin{array}{r}
x_{i t}^{L}=x_{i, t-1}^{L}+x_{i t}-l_{i t} \quad \forall i, t \\
x_{i 0}^{L}=x_{i 0}^{L^{\prime}} \quad \forall i \\
\sum_{i=1}^{I} o_{i}^{X} x_{i t}^{L} \leq x^{L^{\max }} \quad \forall t
\end{array}
$$

The restricted condition of supplier's material supplying

$$
\sum_{i=1}^{I}\left\{s_{h i}^{r}\left[x_{i t}-\sum_{j=1}^{J}\left(s_{i j}^{y} \alpha_{j t}^{3} R_{j t}\right)\right]\right\} \leq s_{h t} \quad \forall h, t
$$

Manufacturer's capacity restriction at each stage

$$
\sum_{j=1}^{J} \alpha_{j}^{k} z_{j t} \leq K^{\max } \quad \forall t
$$

Manufacturer's inventory of ultimate product at each stage

$$
\begin{gathered}
z_{j t}^{L}=z_{j, t-1}^{L}+z_{j t}-v_{j t}+\alpha_{j t}^{1} R_{j t} \quad \forall j, t \\
z_{j 0}^{L}=z_{j 0}^{L^{\prime}} \quad \forall j \\
\sum_{j=1}^{J} o_{j}^{z} z_{j t}^{L} \leq z^{L^{\max }} \quad \forall t
\end{gathered}
$$

Manufacturer's inventory of material satisfies

$$
\begin{gathered}
y_{i t}^{L}=y_{i, t-1}^{L}+b_{i t}+\sum_{j=1}^{J} s_{i j}^{y}\left(-z_{j t}+\alpha_{j t}^{2} R_{j t}\right) \quad \forall i, t \\
y_{i 0}^{L}=y_{i 0}^{L^{\prime}} \quad \forall i \\
\sum_{i=1}^{I} o_{i}^{y} y_{i t}^{L} \leq y^{L^{\max }} \quad \forall t
\end{gathered}
$$

Manufacturer's actual sales satisfies

$$
v_{j t} \leq d_{j t} \quad \forall j, t
$$

Relationship between demand of ultimate product and its price

$$
d_{j t}=d_{j}-\alpha_{j} p_{j t}-\beta_{j}\left(p_{j t}-p_{j, t-1}\right)
$$

Relationship between collecting quantity of used product and its collecting price

$$
R_{j t}=e_{j}+\varepsilon r_{j t}+\eta\left(r_{j t}-r_{j, t-1}\right)
$$

Nonnegative conditions:

$$
\begin{aligned}
& b_{i t}, z_{j t}, z_{j t}^{L}, y_{i t}^{L}, l_{i t}, x_{i t}^{L}, p_{j t}, r_{j t}, d_{i t}^{-}, d_{i t}^{+}, d_{P}^{-}, \\
& d_{P}^{+}, d_{S}^{-}, d_{S}^{+}, C^{P}, C^{S}, v_{j t}^{S}, x_{i t} \geq 0 \quad \forall i, j, t
\end{aligned}
$$

\section{Simulations}

Set $J=1$ (one ultimate product), $I=1$ (one material), $H=$ 1 (one raw material) and $T=4$ (four stages).
Demand of ultimate product neglecting the impacts of sale price and vendition effort is $d=450$, collecting quantity of used product neglecting the collecting price and collecting efforts is $e=100$, demand sensitive coefficients of product to the sale's price and its variation are $\alpha=0.5$ and $\beta=5$ respectively. Collecting quantity Sensitive coefficients of used product to collecting price and its variation are $\varepsilon=2$ and $\eta=20$ respectively.

Expected profits of manufacturer and supplier are all $1 \times 10^{8}$, that is, $M_{P}=1 \times 10^{8}$ and $M_{S}=1 \times 10^{8}$. The supply quantity of raw material at each stage are all 400 , initial price of ultimate product is $p_{0}=300$, the prices of raw material at each stage are all 40 .

Repairing rate, disassembling rate and decomposing rate of used product are $\alpha_{t}^{1}=20 \%, \alpha_{t}^{2}=30 \%$ and $\alpha_{t}^{3}=30 \% \quad(t=1,2,3,4)$ respectively. Initial collecting price of used product is $r_{0}=20$, unit cost for repairing, disassembling and decomposing used product are $\gamma_{t}^{1}=3$, $\gamma_{t}^{2}=8$ and $\gamma_{t}^{3}=20$ respectively. The raw material from decomposing used product can be sold to supplier, and its price are all $w_{t}=30 \quad(t=1,2,3,4)$. Other parameters are set as below.

$$
\begin{gathered}
K^{\max }=400, G^{\max }=400 \\
z^{L^{\max }}=50, y^{L^{\max }}=50, x^{L^{\max }}=50 \\
z_{0}^{L^{\prime}}=0, y_{0}^{L^{\prime}}=0, x_{0}^{L^{\prime}}=0 \\
c^{x}=10, c^{z}=15, q=75 \\
h^{x}=1, h^{y}=2, h^{z}=3 \\
\alpha^{g}=1, \alpha^{k}=1, s^{r}=1, s^{y}=1 \\
o^{x}=1, o^{y}=1, o^{z}=1
\end{gathered}
$$

We used LINGO9.0 for solving our multi-objective dynamic programming model. The results are shown in Tables 1 and 2.

From results in Table 1, we can see that supplier's delivery quantity of material equals to manufacturer's order quantity at each stage. The amount of sales quantity and inventory is bigger than the output of ultimate product at each stage, and the difference of these is increasing along with operation stage. The reasons for this phenomenon is that, as time increases, price of ultimate product and collecting price of used product become gradually rationalize, demand of the ultimate product increases gradually, and the collecting quantity of used product is also increasing.

As results in Table 2 shown, when initial price of ultimate product is set 300 , except stage 1 , the price of ultimate product decreases as time goes on, but the demand of ultimate product increase. When initial collecting price of used product is set 20, except stage 1 and stage 2 , collecting price of used product increases gradu- 
Table 1. Optimal operation strategy for the closed-loop supply chain system.

\begin{tabular}{|c|c|c|c|c|c|c|c|c|}
\hline \multirow[b]{2}{*}{ Stage } & \multicolumn{5}{|c|}{ Manufacturer (Profits: 297061.1) } & \multicolumn{3}{|c|}{ Supplier (Profits: 25341.0) } \\
\hline & $\begin{array}{c}\text { outputs of } \\
\text { ultimate } \\
\text { product }\end{array}$ & $\begin{array}{l}\text { Sales quantity } \\
\text { of ultimate } \\
\text { product }\end{array}$ & $\begin{array}{c}\text { Inventories of } \\
\text { ultimate } \\
\text { product }\end{array}$ & $\begin{array}{c}\text { Inventory of } \\
\text { materials }\end{array}$ & $\begin{array}{l}\text { Orders of } \\
\text { materials }\end{array}$ & $\begin{array}{l}\text { Materials } \\
\text { deliveries }\end{array}$ & $\begin{array}{c}\text { Materials } \\
\text { production }\end{array}$ & $\begin{array}{l}\text { Materials } \\
\text { inventory }\end{array}$ \\
\hline 1 & 187.5 & 190.4 & 0 & 0 & 183.0 & 183.0 & 183.0 & 0 \\
\hline 2 & 400.0 & 363.4 & 50 & 0 & 379.9 & 379.9 & 379.9 & 0 \\
\hline 3 & 400.0 & 433.7 & 50 & 0 & 349.4 & 349.4 & 349.4 & 0 \\
\hline 4 & 400.0 & 513.2 & 0 & 0 & 305.2 & 305.2 & 305.2 & 0 \\
\hline
\end{tabular}

Table 2. Demands of ultimate product and collecting quantities of used product.

\begin{tabular}{ccccc}
\hline Stage & Prices of ultimate product & Demands of ultimate product & \multicolumn{2}{c}{$\begin{array}{c}\text { Collecting prices of used } \\
\text { product }\end{array}$} \\
\hline 1 & 319.9 & 190.4 & 9.6 & \multicolumn{2}{c}{$\begin{array}{c}\text { Collecting quantities of used } \\
\text { product }\end{array}$} \\
2 & 306.6 & 363.4 & 14.2 & 10.1 \\
3 & 281.7 & 433.7 & 26.0 \\
4 & 244.6 & 513.2 & 168.6 & 316.0 \\
\hline
\end{tabular}

ally, and so does collecting quantity of used product. The varying tendency for the price of ultimate product and the collecting price of used product are shown as Figures 2 and 3 respectively.

According to parameters above, whatever initial price of ultimate product and collecting price of used product are, we can obtain the same conclusions from the model: in the long run, through the regulations of price itself and price reference effect, the price of ultimate product is fixed to 157.2707 and the collecting price of used product is fixed to 27.38714 .

\section{Conclusions}

From the view of operation researches, we consider a class of closed-loop supply chain system with product remanufacturing. The system is consists of one manufacturer and one supplier. The manufacturer is in charge of recollecting and re-disposal the used products. Demands of ultimate products and collecting quantity of used products are described by using prices and refer-

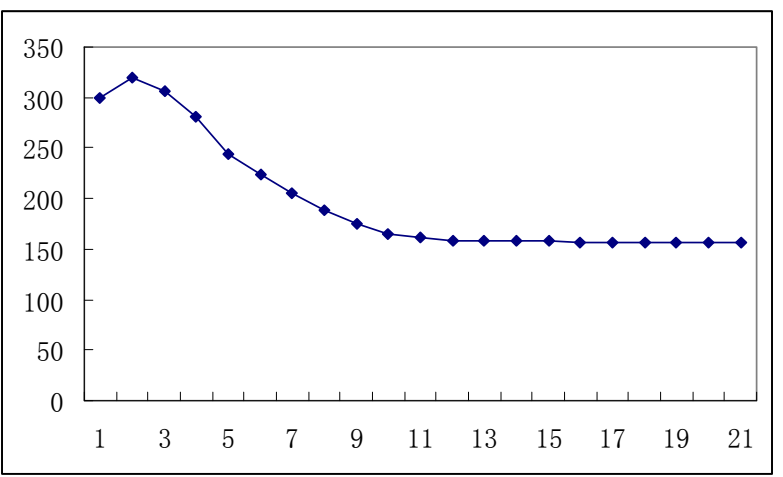

Figure 2. The varying tendency for the price of ultimate product.

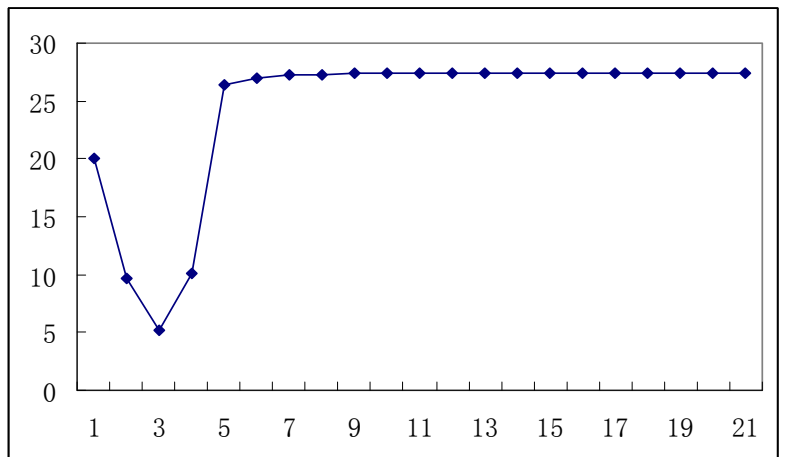

Figure 3. The varying tendency for collecting price of used product.

ence prices. A non-linear dynamic pricing model for system operation is established. The model is constructed as a dynamic programming problem and satisfying several conflict objectives, such as the operating coordination of system, making the maximum profit of all participants as much as possible. The model's validity to dynamic pricing for closed-loop supply chain system is verified by a numerical example. The results of the numerical example shows that, in the long run, through the regulations of price itself and price reference effect, the price of ultimate product and the collecting price of used product fix to a certain value without reference to the initial price of ultimate product and the collecting price of used product.

\section{Acknowledgements}

This work was supported by Humanities \& Social Sciences Planning Fundation of Ministry of Education Grant \#11YJA630165 to J. W. Xu, and China Postdoctoral Science Foundation Grant \#2008044170 to J. W. Xu. 


\section{References}

[1] G. Ferrer and R. U. Ayres, "The Impact of Remanufacturing in the Economy,” Ecological Economics, Vol. 32, No. 3, 2000, pp. 413-429. doi:10.1016/S0921-8009(99)00110-X

[2] E. Sundin and B. Bras, "Making Functional Sales Environmentally and Economically Beneficial through Product Remanufacturing," Journal of Cleaner Production, Vol. 13, No. 9, 2005, pp. 913-925. doi:10.1016/j.jclepro.2004.04.006

[3] M. Fleischmann, J. M. Bloemhof-Ruwarrd, R. Dekker, et al., "Quantitative Models for Reverse Logistics: A Review,” European Journal of Operational Research, Vol. 103, No. 1, 1997, pp. 1-17. doi:10.1016/S0377-2217(97)00230-0

[4] E. Der Laan and M. Salomon, "Production Planning and Inventory Control with Remanufacturing and Disposal," European Journal of Operational Research, Vol. 102, No. 2, 1997, pp. 264-278. doi:10.1016/S0377-2217(97)00108-2

[5] V. Jayaraman, R. A. Patterson and E. Rolland, “The Design of Reverse Distribution Networks: Models and Solution Procedures," European Journal of Operational Research, Vol. 150, No. 1, 2003, pp. 128-149.

\section{doi:10.1016/S0377-2217(02)00497-6}

[6] K. Kim, I. Song, J. Kim and B. Jeong, "Supply Planning Model for Remanufacturing System in Reverse Logistics Environment," Computers \& Industrial Engineering, Vol. 51, No. 2, 2006, pp. 279-287. doi:10.1016/j.cie.2006.02.008

[7] S. Ray and T. Boyaci, "Optimal Prices and Trade-in Rebates for durable, Remanufacturable Products," Manufacturing \& Service Operations Management, Vol. 7, No. 3, 2005, pp. 208-228. doi:10.1287/msom.1050.0080

[8] Q. Gu, T. Gao and L. Shi, "Price Decision Analysis for Reverse Supply Chain Based on Game Theory," Systems Engineering-Theory \& Practice, Vol. 20, No. 3, 2005, pp. 20-25.

[9] T. Guide, "Matching Demand and Supply to Maximize Profits from Remanufacturing," Manufacturing \& Service Operations Management, Vol. 5, No. 4, 2003, pp. 303316. doi:10.1287/msom.5.4.303.24883

[10] K. M. Samar, "Reverse Logistics in e-Business,” International Journal of Physical Distribution \& Logistics Management, Vol. 34, No. 2, 2004, pp. 70-88.

[11] Y. Liang, S. Pokharel, G. H. Lim, "Pricing Used Products for Remanufacturing," European Journal of Operational Research, Vol. 193, No. 2, 2009, pp. 390-395. doi:10.1016/j.ejor.2007.11.029 